\title{
OBSERVER LINIER POSITIF UNTUK SISTEM LINIER POSITIF
}

\author{
TRI UTAMI, ZULAKMAL \\ Program Studi Matematika, \\ Fakultas Matematika dan Ilmu Pengetahuan Alam, Universitas Andalas, \\ Kampus UNAND Limau Manis Padang, Indonesia, \\ triutami55@gmail.com
}

Abstrak. Suatu observer untuk sistem

$$
\begin{aligned}
& \dot{\mathbf{x}}(t)=A \mathbf{x}(t)+B \mathbf{u}(t), \\
& \mathbf{y}(t)=C \mathbf{x}(t), t \geq 0
\end{aligned}
$$

didefinisikan sebagai suatu persamaan diferensial yang berbentuk

$$
\dot{\widehat{\mathbf{x}}}(t)=(A-E C) \widehat{\mathbf{x}}(t)+B \mathbf{u}(t)+E \mathbf{y}(t),
$$

untuk suatu matriks $E \in \mathbb{R}^{n \times p}$, dimana $\widehat{\mathbf{x}}(t) \in \mathbb{R}^{n}$ berperan sebagai estimator untuk vektor keadaan $\mathbf{x}(t)$ dengan estimasi error $\varepsilon(t)$ adalah

$$
\varepsilon(t)=\widehat{\mathbf{x}}(t)-\mathbf{x}(t) .
$$

Estimasi yang baik mestilah memenuhi $\varepsilon(t) \rightarrow \mathbf{0}$ bila $t \rightarrow \infty$, atau $\widehat{\mathbf{x}}(t) \rightarrow \mathbf{x}(t)$ bila $t \rightarrow \infty$. Jika sistem (0.1) adalah positif, persamaan (0.2) dikatakan observer linier positif untuk sistem (0.1) jika $\widehat{\mathbf{x}}(t) \in \mathbb{R}_{+}^{n}$. Pada makalh ini akan dikaji masalah penentuan observer linier positif untuk sistem linier positif. Akan dikaji syarat yang menjamin eksistensi matriks $E \in \mathbb{R}_{+}^{n \times p}$ sedemikian sehingga $\widehat{\mathbf{x}}(t) \in \mathbb{R}_{+}^{n}$ dan $\varepsilon(t) \rightarrow \mathbf{0}$ bila $t \rightarrow \infty$.

Kata Kunci: Sistem linier positif, observer, matriks Metzler

\section{Pendahuluan}

Diberikan suatu sistem kontrol linier

$$
\begin{aligned}
& \dot{\mathbf{x}}(t)=A \mathbf{x}(t)+B \mathbf{u}(t), \\
& \mathbf{y}(t)=C \mathbf{x}(t), \quad t \geq 0
\end{aligned}
$$

dimana $\mathbf{x}(t) \in \mathbb{R}^{n}$ menyatakan vektor keadaan, $\mathbf{u}(t) \in \mathbb{R}^{m}$ menyatakan vektor kontrol dan $\mathbf{y}(t) \in \mathbb{R}^{p}$ menyatakan vektor output. $A \in \mathbb{R}^{n \times n}, B \in \mathbb{R}^{n \times m}$ dan $C \in \mathbb{R}^{p \times n}$. Sistem (1.1) dikatakan positif jika $\mathbf{x}(t)$ dan $\mathbf{y}(t)$ adalah nonnegatif untuk setiap keadaan awal nonnegatif $\mathbf{x}_{0}$ dan setiap kontrol nonnegatif $\mathbf{u}(t), t \geq 0$ [2]. Dalam [5], dinyatakan bahwa sistem (1.1) adalah positif jika dan hanya jika $A \in \mathcal{M}^{n}, B \in \mathbb{R}_{+}^{n \times m}$ dan $C \in \mathbb{R}_{+}^{p \times n}$.

Suatu observer untuk sistem (1.1) didefinisikan sebagai suatu persamaan diferensial yang berbentuk sebagai berikut:

$$
\dot{\widehat{\mathbf{x}}}(t)=(A-E C) \widehat{\mathbf{x}}(t)+B \mathbf{u}(t)+E \mathbf{y}(t),
$$


untuk suatu matriks $E \in \mathbb{R}^{n \times p}$, dimana $\widehat{\mathbf{x}}(t) \in \mathbb{R}^{n}$ [2]. Dalam [2] dinyatakan bahwa vektor $\widehat{\mathbf{x}}(t)$ berperan sebagai estimator untuk vektor keadaan $\mathbf{x}(t)$ dengan estimasi error $\varepsilon(t)$ adalah

$$
\varepsilon(t)=\widehat{\mathbf{x}}(t)-\mathbf{x}(t)
$$

Estimasi yang baik mestilah memenuhi $\varepsilon(t) \rightarrow \mathbf{0}$ bila $t \rightarrow \infty$, atau $\widehat{\mathbf{x}}(t) \rightarrow \mathbf{x}(t)$ bila $t \rightarrow \infty$. Jika sistem (1.1) adalah positif, persamaan (1.2) dikatakan observer linier positif untuk sistem (1.1) jika $\widehat{\mathbf{x}}(t) \in \mathbb{R}_{+}^{n}$. Pada makalh ini akan dikaji masalah penentuan observer linier positif untuk sistem linier positif. Akan dikaji syarat yang menjamin eksistensi matriks $E \in \mathbb{R}_{+}^{n \times p}$ sedemikian sehingga $\widehat{\mathbf{x}}(t) \in \mathbb{R}_{+}^{n}$ dan $\varepsilon(t) \rightarrow \mathbf{0}$ bila $t \rightarrow \infty$.

\section{Observer Linier Positif untuk Sistem Linier Positif}

Berikut diberikan definisi matriks Metzler.

Definisi 2.1. Suatu matriks $A$ berukuran $n \times n$ dikatakan matriks Metzler jika semua entri selain diagonal utamanya adalah nonnegatif, yaitu $a_{i j} \geq 0, \forall i \neq j$; $i, j=1,2, \ldots, n$.

Teorema 2.2. Misalkan A adalah suatu matriks Metzler, maka terdapat suatu $\mu_{0} \in$ $\mathbb{R}$ dan suatu $\mathbf{x}_{0} \in \mathbb{R}_{+}^{n}$ sedemikian sehingga

(1) $A \boldsymbol{x}_{0}=\mu_{0} \boldsymbol{x}_{0}$.

(2) Jika $\mu \neq \mu_{0}$ adalah nilai eigen lain dari $A$, maka $\operatorname{Re}(\mu)<\mu_{0}$.

Dari sistem (1.1), misalkan matriks $A$ adalah nonnegatif. Sistem (1.1) dikatakan stabil asimtotik jika solusinya menghampiri 0 bila $t$ menuju tak hingga, yaitu $\lim _{t \rightarrow \infty} \mathbf{x}(t)=0$. Dalam beberapa literatur dinyatakan bahwa untuk menguji kestabilan asimtotik dari sistem (1.1) cukup dengan melihat nilai eigen dari matriks $A$. Jika bagian riil dari semua nilai eigen dari matriks $A$ adalah negatif maka sistem (1.1) adalah stabil asimtotik, demikian juga sebaliknya [4].

Lema berikut memberikan kondisi stabil untuk matriks Metzler:

Lema 2.3. Suatu matriks Metzler $A \in \mathcal{M}^{n}$ adalah stabil asimtotik jika semua elemen diagonalnya negatif.

Berikut disajikan syarat perlu dan syarat cukup untuk eksistensi observer linier positif konvergen untuk sisitem linier positif dengan output tunggal.

Lema 2.4. Diberikan suatu matriks Metzler $A \in \mathcal{M}^{n}$ dan suatu matriks nonnegatif $C \in \mathbb{R}_{+}^{1 \times n}$. Jika terdapat matriks nonnegatif $E \in \mathbb{R}_{+}^{n \times 1}$ sedemikian sehingga ( $A-$ $E C)$ adalah matriks Metzler stabil asimtotik, maka

$$
a_{i i} c_{j}<a_{i j} c_{i}, \forall i, \forall j \neq i \text {, sedemikian sehingga } c_{j} \neq 0 .
$$


Bukti. Pilih matriks $E \in \mathbb{R}_{+}^{n \times 1}$, dengan

$$
E=\left(\begin{array}{c}
e_{1} \\
e_{2} \\
\vdots \\
e_{n}
\end{array}\right)
$$

dimana $e_{i} \geq 0, \forall i=1,2, \ldots, n$ dan ada $j \in\{1,2, \ldots, n\}$ sedemikian sehingga $e_{j}>0$. Karena diinginkan $(A-E C) \in \mathcal{M}^{n}$ maka matriks $\left(a_{i j}-e_{i} c_{j}\right) \geq 0, \forall i \neq j$, atau dapat ditulis

$$
e_{i} c_{j} \leq a_{i j}, \forall i \neq j
$$

Selanjutnya, karena diinginkan pula matriks $(A-E C)$ adalah stabil asimtotik, maka haruslah $a_{i i}-e_{i} c_{i}<0, \forall i$, atau dapat ditulis

$$
e_{i} c_{i}>a_{i i} .
$$

Jika $c_{i}>0$ dan $c_{j}>0$, maka dari (2.3) diperoleh

$$
a_{i i} c_{j}<e_{i} c_{i} c_{j},
$$

dan dari (2.2) diperoleh

$$
a_{i i} c_{j}<e_{i} c_{i} c_{j}<a_{i j} c_{i}
$$

yang memperlihatkan hubungan (2.1) terpenuhi.

Teorema berikut memberikan syarat yang menjamin eksistensi matriks $E$ untuk observer linier positif konvergen.

Teorema 2.5. Diberikan suatu matriks Metzler $A \in \mathcal{M}^{n}$ dan suatu matriks nonnegatif $C \in \mathbb{R}_{+}^{1 \times n}$. Misalkan $E \in \mathbb{R}_{+}^{n \times 1}$ adalah suatu matriks nonnegatif dengan entri-entri $e_{i}$ sedemikian sehingga

$$
\begin{gathered}
e_{i}>\frac{a_{i i}}{c_{i}}, \text { jika } c_{j}=0, \forall j \neq i, \\
e_{i}=\min _{j \neq i, c_{j} \neq 0}\left\{\frac{a_{i j}}{c_{j}}\right\}, \text { jika } c_{j} \neq 0 .
\end{gathered}
$$

Maka terdapat observer linier positif konvergen untuk sistem (1.1) jika dan hanya jika $\lambda_{\max }(A-E C)<0$.

Bukti. $(\Leftarrow)$ Pemilihan matriks $E \in \mathbb{R}_{+}^{n}$ dengan entri-entri yang memenuhi $(2.4)$ dan (2.5) menjamin bahwa $(A-E C)$ merupakan suatu matriks Metzler. Karena $\lambda_{\max }(A-E C)<0$, maka matriks $(A-E C)$ adalah stabil asimtotik, sehingga matriks $E$ ini dapat digunakan untuk membentuk suatu observer linier positif konvergen. $(\Rightarrow)$ Misalkan

$$
\dot{\hat{\mathbf{x}}}(t)=(A-E C) \widehat{\mathbf{x}}(t)+B \mathbf{u}(t)+E \mathbf{y}(t)
$$

adalah suatu observer linier positif konvergen untuk sistem (1.1), maka $(A-E C)$ adalah matriks Metzler dan stabil asimtotik. Karena $(A-E C)$ adalah matriks 
Metzler, maka matriks $(A-E C)$ memiliki nilai eigen riil terbesar $\lambda_{\max }$ sedemikian sehingga $\operatorname{Re}(\lambda)<\lambda_{\max }$ untuk setiap $\lambda \in\{\gamma: \operatorname{det}(A-E C-\gamma I)=0\}$. Selanjutnya, karena $(A-E C)$ merupakan matriks yang stabil asimtotik maka $\operatorname{Re}(\lambda)<0$ untuk setiap $\lambda \in\{\gamma: \operatorname{det}(A-E C-\gamma I)=0\}$. Akibatnya $\lambda_{\max }<0$.

Contoh berikut akan mengilustrasikan suatu sistem yang memiliki observer dengan $n \geq 3$ :

Contoh 1. Diberikan suatu sistem linier, dimana

$$
A=\left(\begin{array}{lll}
2 & 6 & 4 \\
5 & 4 & 8 \\
4 & 9 & 2
\end{array}\right), B=\left(\begin{array}{l}
0 \\
0 \\
1
\end{array}\right), C=\left(\begin{array}{lll}
1 & 2 & 1
\end{array}\right)
$$

Misalkan $E=\left(\begin{array}{c}e_{1} \\ e_{2} \\ e_{3}\end{array}\right)$, maka

$$
\begin{aligned}
(A-E C) & =\left(\begin{array}{lll}
2 & 6 & 4 \\
5 & 4 & 8 \\
4 & 9 & 2
\end{array}\right)-\left(\begin{array}{l}
e_{1} \\
e_{2} \\
e_{3}
\end{array}\right)\left(\begin{array}{lll}
1 & 2 & 1
\end{array}\right) \\
& =\left(\begin{array}{lll}
2 & 6 & 4 \\
5 & 4 & 8 \\
4 & 9 & 2
\end{array}\right)-\left(\begin{array}{lll}
e_{1} & 2 e_{1} & e_{1} \\
e_{2} & 2 e_{2} & e_{2} \\
e_{3} & 2 e_{3} & e_{3}
\end{array}\right)
\end{aligned}
$$

Sehingga diperoleh matriks

$$
E=\left(\begin{array}{l}
3 \\
5 \\
4
\end{array}\right)
$$

dengan demikian

$$
\begin{aligned}
(A-E C) & =\left(\begin{array}{lll}
2 & 6 & 4 \\
5 & 4 & 8 \\
4 & 9 & 2
\end{array}\right)-\left(\begin{array}{l}
3 \\
5 \\
4
\end{array}\right)\left(\begin{array}{lll}
1 & 2 & 1
\end{array}\right) \\
& =\left(\begin{array}{ccc}
-1 & 0 & 1 \\
0 & -6 & 3 \\
0 & 1 & -2
\end{array}\right)
\end{aligned}
$$

Dari matriks $(A-E C)$ diperoleh $\lambda_{\max }(A-E C)=-1$, maka terdapat suatu observer linier positif konvergen untuk sistem linier positif (1.1). Observernya adalah

$$
\left(\begin{array}{c}
\dot{\widehat{x}}_{1}(t) \\
\hat{\widehat{x}}_{2}(t) \\
\dot{\widehat{x}}_{3}(t)
\end{array}\right)=\left(\begin{array}{ccc}
-1 & 0 & 1 \\
0 & -6 & 3 \\
0 & 1 & -2
\end{array}\right)\left(\begin{array}{c}
\widehat{x}_{1}(t) \\
\widehat{x}_{2}(t) \\
\widehat{x}_{3}(t)
\end{array}\right)+\left(\begin{array}{l}
0 \\
0 \\
1
\end{array}\right) u(t)+\left(\begin{array}{l}
3 \\
5 \\
4
\end{array}\right) y(t),
$$


dan persamaan errornya adalah

$$
\dot{\varepsilon}(t)=\left(\begin{array}{ccc}
-1 & 0 & 1 \\
0 & -6 & 3 \\
0 & 1 & -2
\end{array}\right) \varepsilon(t) .
$$

\section{Penutup}

Syarat yang menjamin eksistensi observer linier positif konvergen untuk sistem linier positif adalah terdapatnya entri-entri matriks $E$ yang memenuhi hubungan

$$
\begin{gathered}
e_{i}>\frac{a_{i i}}{c_{i}}, \text { jika } c_{j}=0, \forall j \neq i, \\
e_{i}=\min _{j \neq i, c_{j} \neq 0}\left\{\frac{a_{i j}}{c_{j}}\right\}, \text { jika } c_{j} \neq 0
\end{gathered}
$$

sedemikian sehingga $\lambda_{\max }(A-E C)<0$.

\section{Ucapan Terima kasih}

Penulis mengucapkan terima kasih kepada Bapak Dr. Mahdhivan Syafwan, Bapak Bukti Ginting, M.Si, dan Bapak Efendi, M.Si yang telah memberikan masukan dan saran sehingga paper ini dapat diselesaikan dengan baik.

\section{Daftar Pustaka}

[1] Anton, H. 1991. Aljabar Linier Elementer Edisi Kedelapan Jilid-1. Erlangga, Jakarta

[2] Bastian. G. and N. Dautrebande. 1999. Positive Linear Observers for Positive Linear Systems. Proceedings European Control Conference ECC'99, Paper F371, Germany

[3] D. G. Luenberger. 1979. Introduction to Dynamic Systems. John Wiley and Sons. New York

[4] Hendricks. Elbert, Ole. Jannerup dan P. H. Sorensen. 2008. Linear Systems Control. Springer

[5] Kaczorek, T. 2012. Existence and Determination of The Set of Metzler Matrices for Given Stable Polynomials. International Journal of Applied Mathematics and Computer Sience. 22 (2): 389 - 399

[6] Leenheer. P. dan D. Aeyels. 2001. Stabilization of Positive Linear Systems. Systems and Control Letters. 44: $259-271$ 